\title{
Validation of the AUDIT scale and factors associated with alcohol use disorder in adolescents: results of a National Lebanese Study
}

Jennifer Hallit', Pascale Salameh" ${ }^{2,3,4}$, Chadia Haddad ${ }^{5,6}$, Hala Sacre ${ }^{2,7}$, Michel Soufia ${ }^{1,4}$, Marwan Akel ${ }^{2,8}$, Sahar Obeid ${ }^{2,5,9 \dagger}$, Rabih Hallit ${ }^{1 \dagger}$ and Souheil Hallit ${ }^{1,2^{*}+}$ (D)

\begin{abstract}
Background: This study objective was to evaluate the prevalence of alcohol use disorder (AUD) and related factors (smoking, internet addiction, social anxiety, child abuse, and bullying) among a representative sample of Lebanese adolescents, and to validate and confirm psychometric properties of the Alcohol Use Disorders Identification Test (AUDIT).

Methods: A cross-sectional study, conducted between January and May 2019, enrolled 1810 adolescents aged between 14 and 17 from schools of all Lebanese districts. From the total number of schools, a proportionate number was selected in each district. AUD was defined as a high AUDIT score ( $\geq 8$; score range 0-40). A principal component analysis technique to confirm the validity of the construct of the AUDIT scale score was done and a confirmatory analysis to assess the structure of the instrument was conducted. Spearman correlation was used for linear correlation between continuous variables. The Mann-Whitney test was used to compare the means of two groups, while the Kruskal-Wallis test was used to compare three groups or more. A stepwise linear regression was conducted, taking the AUDIT total score as the dependent variable and taking child abuse (psychological, sexual, physical and verbal), cigarette and waterpipe smoking dependence, bullying, social phobia, and internet addiction as independent variables.
\end{abstract}

Results: The mean AUDIT score was $6.46 \pm 8.44$ and high risk of AUD was found in 507 (28.0\%) adolescents [95\% CI 0.259-0.301]. One factor solution of the AUDIT scale was found after running the factor analysis $\left(a_{\text {cronbach }}=0.978\right)$. Higher AUDIT scores were significantly associated with higher cigarette (Beta $=0.527 ; p<0.001$ ) and waterpipe (Beta $=0.299 ; p<0.001$ ) dependence, higher childhood sexual abuse (Beta $=0.656 ; p<0.001)$ and neglect (Beta $=$ $0.126 ; p<0.001)$, higher bullying victimization (Beta $=0.236 ; p<0.001)$.

(Continued on next page)

\footnotetext{
* Correspondence: souheilhallit@hotmail.com

+Sahar Obeid, Rabih Hallit and Souheil Hallit contributed equally to this work and are last coauthors.

${ }^{1}$ Faculty of Medicine and Medical Sciences, Holy Spirit University of Kaslik (USEK), Jounieh, Lebanon

${ }^{2}$ INSPECT-LB: Institut National de Santé Publique, Épidémiologie Clinique et Toxicologie, Beirut, Lebanon

Full list of author information is available at the end of the article
}

(c) The Author(s). 2020 Open Access This article is licensed under a Creative Commons Attribution 4.0 International License, which permits use, sharing, adaptation, distribution and reproduction in any medium or format, as long as you give appropriate credit to the original author(s) and the source, provide a link to the Creative Commons licence, and indicate if changes were made. The images or other third party material in this article are included in the article's Creative Commons licence, unless indicated otherwise in a credit line to the material. If material is not included in the article's Creative Commons licence and your intended use is not permitted by statutory regulation or exceeds the permitted use, you will need to obtain permission directly from the copyright holder. To view a copy of this licence, visit http://creativecommons.org/licenses/by/4.0/. The Creative Commons Public Domain Dedication waiver (http://creativecommons.org/publicdomain/zero/1.0/) applies to the data made available in this article, unless otherwise stated in a credit line to the data. 
(Continued from previous page)

Conclusion: Alcohol use disorder among Lebanese adolescents seems to be associated with several factors, such as cigarette and waterpipe dependence, parents' divorce, higher internet addiction, bullying victimization, and childhood sexual abuse and neglect. Parents and healthcare professionals could use this data for early interventions.

Keywords: Alcohol use disorder, AUDIT scale, Arabic version, Bullying, Smoking, Child abuse, Internet addiction

\section{Background}

Adolescence is the transition period from childhood to adulthood, characterized by developing knowledge and skills, learning how to manage emotions and relationships, and earning skills to help appreciate and take on adult roles [1]. During this period, adolescents may face, among other issues, problematic alcohol consumption. Despite its known direct impact on overall health outcomes, Alcohol Use Disorder (AUD) is pervasive and endemic among adolescents and thought to be a pediatric-onset condition (with one in twenty cases fighting with family or friends and skipping school, disclosing problems related to alcohol drinking) requiring early detection and screening to initiate the appropriate intervention the soonest [2, 3]. For example, in 2011, 90\% of European teenagers between 15 and 16 had consumed alcohol at least once in their lifetime [4]. In the United States in 2014, 50.9\% of surveyed adolescents between 12 and 20 were binge drinkers, and 13.7\% were heavy drinkers [4].

The term AUD is now used in the Diagnostic and Statistical Manual of Mental Disorders 5th Edition (DSM-5) to replace alcohol abuse and dependence, previously used in the DSM-4. It is characterized by a dysfunctional alcohol consumption pattern resulting in clinically significant disability or anxiety, as evidenced by various psychosocial, behavioral, or physiological characteristics [5], and accounts for more than 5\% of the global disease burden, as per the World Health Organization (WHO) Global Status Report on Alcohol and Health 2018 [6].

Multiple factors were found to be correlated with AUD among adolescents, such as cigarette smoking; although AUD and smoking usually co-occur, studies showed that smoker adolescents have a higher vulnerability to AUDs [7, 8]. Other factors include internet addiction [9], social anxiety [10], child abuse [11, 12], and bullying victimization $[13,14]$.

Social anxiety, defined as the extreme fear of being negatively assessed by others, has been reported as a potentially significant factor affecting alcohol use and smoking in adolescents [10], but the association between anxiety disorders and teenage alcohol consumption is still not clear [15].

Another factor related to AUD is child maltreatment. It includes several subtypes: sexual, physical, and emotional abuse, and neglect. Studies revealed that unfavorable childhood was associated with two significant public health risks, AUD and substance use disorder. It was suggested that among the four forms of childhood maltreatment, emotional abuse could be the principal driver of pathological drinking among victims of child abuse [16]. Further research disclosed that psychological, physical, and sexual abuse were associated with increased alcohol use among adolescents and an increase in the likelihood that a substance use disorder will occur later in life $[11,12]$.

Bullying victimization, whether physical, verbal, relational, or cyberbullying, was also linked to higher AUD. At some point in their life, about $15-30 \%$ of youth reported having been intimated $[17,18]$. According to the type of aggression, victims may experience variable issues of mental wellbeing [19], including suicidal ideation [20], alcohol use and illegitimate drug use [13].

In Eastern Mediterranean countries, where Islam is the predominant religion, alcohol consumption is closely linked to religious beliefs [21]. Therefore, it is believed that, because it is prohibited by Islam, alcohol consumption is underestimated in these conservative societies, where talking about alcohol is still a taboo [21]. A systematic review outlined that in Lebanon, epidemiological work on alcohol consumption and its effects could be carried out because of religious diversity and a more liberal society [22]. Moreover, the Lebanese context largely affects alcohol use among young people. Indeed, alcohol policies are poorly implemented despite laws and regulations, dating back to the 1940s and 1960s, prohibiting the sale of alcohol to minors [2]. As per these regulations, penalties and fines are as low as $\$ 4$ for individuals promoting alcoholic beverages to minors under the age of eighteen, and \$ 13 for owners and staff of bars, pubs, or other public places selling alcohol to minors, or making them drunk [2]. Moreover, alcoholic beverages are inexpensive and easily accessible [2].

In Lebanon, the majority of studies have evaluated the prevalence of alcohol consumption and its consequences among adults but not in young people [23, 24]. Nonetheless, few alcohol-related research among Arab and Lebanese adolescents could be gathered [2]. The results of the Global School-based Student Health Survey (GSHS) [25] in schoolchildren aged 13-17 years from 73 
countries, including 16 in the Eastern Mediterranean region, showed that among those who drank alcohol, the majority had their first drink before the age of 14, and a substantial percentage got intoxicated at least once in their lifetime [2, 25].

To assess alcohol consumption, drinking habits, and other alcohol-related issues, the WHO developed a 10item tool, the Alcohol Use Disorders Identification Test (AUDIT) [26]. This validated questionnaire is widely used across countries to evaluate hazardous drinking and alcohol consumption patterns [27] that increase the risk of physical, mental, and social harm in adults and adolescents $[28,29]$. It has been validated among prisoners in the United Arab Emirates [30] and university students in Lebanon [31], but there is no information about its validation among Lebanese adolescents. Moreover, no study had evaluated yet the prevalence and the variables related to AUD among adolescents in Lebanon, taking into account the extent of alcohol-related public health burden and the associated morbidity and mortality.

Therefore, our study aims to evaluate the prevalence of AUD and related factors (smoking, internet addiction, social anxiety, child abuse, and bullying victimization) among a representative sample of Lebanese adolescents, and to validate and confirm psychometric properties of the AUDIT scale.

\section{Methods}

\section{Participants}

This cross-sectional study was carried out between January and May 2019 and enrolled participants from schools of all Lebanese districts (Beirut, Mount Lebanon, Central, South, and Bekaa). The Ministry of Education and Higher Education in Lebanon provided the list of schools. From the total number of schools, a proportionate number was selected in each district; no replacement was made when a school refused to participate. A total of 18 private schools was contacted; 2 refused to participate. The schools that agreed were located as follows: 4 in Beirut, 2 in South Lebanon, 6 in Mount Lebanon, 2 in North Lebanon, and 2 in Bekaa. All students aged 14 to 17 , who were physically present on the day the survey was administered, were eligible. Students were free to accept or refuse to participate, and no financial compensation was offered in return to those who participated. Excluded were the students who refused to fill out the questionnaire. The methodology used in this study is similar to that in previous papers [32-56].

\section{Minimal sample size}

In the absence of similar studies in the country, it was hypothesized that waterpipe smoking would have a medium effect $(r=0.3)$ on increasing AUD. The G- power software calculated a minimum sample of 134 participants, considering a power of $95 \%$.

\section{Questionnaire}

The self-administered questionnaire used was in Arabic, the native language of Lebanon, and required approximately 60 min to complete. Students were asked to fill it out in class to avoid their parents' influence when answering the questions. A member of the research team was available in the classroom to clarify questions that were not understood by the students. At the end of the process, the completed questionnaires were collected back in closed boxes and sent for data entry. The anonymity of the participants was guaranteed during the data collection process.

The first part of the questionnaire evaluated the participants' sociodemographic information (i.e., age, gender, smoking status, parents' status), in addition to the Body Mass Index (BMI) and the household crowding index. The BMI $\left(\mathrm{kg} / \mathrm{m}^{2}\right)$ was calculated based on selfreported heights and weights of participants, and the household crowding index by dividing the number of persons living in the house by the number of rooms, excluding the bathroom and the kitchen [57].

The second part of the questionnaire was composed of the different scales used:

\section{The alcohol use disorders identification test (AUDIT)}

This self-reported tool assesses alcohol use, drinking patterns, and alcohol-related issues [58]. Hazardous alcohol drinking (HAD) is considered when participants score 8 or more. In this study, $\alpha_{\text {Cronbach }}=0.978$.

\section{Liebowitz social anxiety scale (LSAS)}

This self-reported scale features 24 items graded on a Likert scale from 0 to 3, divided into two subcategories (13 questions about performance anxiety, and 11 about social situations) $[59,60]$. In this study, $\alpha_{\text {Cronbach }}$ total score $=0.969, \alpha_{\text {Cronbach }}$ fear subscale $=0.952, \alpha_{\text {Cronbach }}$ avoidance subscale $=0.951$.

\section{Internet addiction test (IAT)}

The Arabic version [61] validated among Lebanese adolescents [62] was used. It consists of 20 items scored on a Likert scale from $0=$ does not apply/never to $5=\mathrm{al}-$ ways applies. Higher scores defining higher internet addiction. In this study, $\alpha_{\text {Cronbach }}=0.925$.

\section{Lebanon Waterpipe dependence Scale-11 (LWDS-11)}

The LWDS-11 test was used to assess waterpipe dependence [63]. It consists of 11 items measured on a 4-point Likert scale from 0 to 3 , with higher scores reflecting higher waterpipe dependence. In this study, $\alpha_{\text {Cronbach }}=$ 0.888 . 


\section{Fagerström test for nicotine dependence (FTND)}

This scale consists of 6 items, three dichotomous (yes/ no) scored 0 and 1 , and three multiple-choice measured from 0 to 3 . The higher the total Fagerström score, the more intense the physical dependence on nicotine [64]. In this study $\alpha_{\text {Cronbach }}=0.825$.

\section{Child abuse self-report scale (CASRS)}

This 38-item tool is divided into 4 subscales of child abuse: psychological abuse (14 items), neglect (11 items), physical abuse ( 8 items), and sexual abuse (5 items) and scored on a 4-point Likert scale $(0=$ Never, $1=$ Sometimes, $2=$ Most often, $3=$ Always) [65], with higher scores indicating more childhood abuse [66]. In this study, the Cronbach's alpha values for each subscale were as follows: $\alpha_{\text {Cronbach }}$ psychological abuse $=0.973$, $\alpha_{\text {Cronbach }}$ neglect $=0.971, \quad \alpha_{\text {Cronbach }}$ physical abuse $=$ 0.966 , and $\alpha_{\text {Cronbach }}$ sexual abuse $=0.954$.

\section{The Illinois bully scale (IBS)}

The bullying victimization subscale was used in this study by directly surveying students [67], with higher scores reflecting higher bullying victimization. In this study, $\alpha_{\text {Cronbach }}=0.975$.

\section{Translation procedure of the questionnaire}

Except for the IAT already available in Arabic, a forward and backward translation was performed for all the scales by two translators, one translator for the translation from English to Arabic, and the other for the back translation. Discrepancies between the original and translated English versions were resolved by consensus.

\section{Statistical analysis}

Data analysis was performed on SPSS software version 25. The AUDIT score, taken as a continuous variable, was considered as the outcome variable, whereas sociodemographic variables and the scales described previously were considered as explanatory variables. Spearman correlation was used for linear correlation between continuous variables. The Mann-Whitney test was used to compare the means of two groups, while the Kruskal-Wallis test was used to compare three groups or more. To adjust for multiple testing, the $p$-value was set using the Bonferroni correction: $p=\alpha / \mathrm{m}$, where $\alpha$ is the desired overall alpha level $(\alpha=0.05)$ and $\mathrm{m}$ is the number of hypotheses/tests conducted $(m=23)$ [68]; thus, the calculated $\mathrm{p}$-value was $0.05 / 23=0.002$. A stepwise linear regression was conducted, taking the AUDIT total score as the dependent variable. To minimize confounding, independent variables entered in the final model were those that showed a $p<0.1$ in the bivariate analysis [69]. A $p<0.05$ was considered significant.
A principal component analysis was performed to confirm the validity of the construct of the AUDIT scale score in the Lebanese population. The exploratory analysis for the validation of the AUDIT scale was conducted on half of the sample (subsample 1: $n=905$ ), and the confirmatory analysis on the other half (subsample 2: $n=905)$. The total sample $(n=1810)$ was used for the bivariate and multivariable analysis. The Kaiser-MeyerOlkin measurement of sampling adequacy and Bartlett's sphericity test were appropriate. The factors retained corresponded to Eigenvalues greater than one.

Second, a confirmatory factor analysis was carried out in subsample 2 using the maximum likelihood method for discrepancy function to assess the structure of the instrument. Several goodness of fit indicators were reported: the Relative Chi-square $\left(\mathrm{x}^{2} / \mathrm{df}\right)$ that serves as goodness of fit index (cut-off values: $<2-5$ ), the Root Mean Square Error of Approximation (RMSEA) that tests the fit of the model to the covariance matrix (close and acceptable fit are considered for values $<0.05$ and $<$ 0.11 , respectively), the Goodness of Fit Index (GFI), and the Adjusted Goodness of Fit Index (AGFI) (acceptable values are $\geq 0.90,[70]$ ). Cronbach's alpha was also recorded to assess the reliability analysis of the total score and subscale factors.

\section{Results}

Out of 2000 questionnaires distributed, 1810 (90.5\%) were completed and collected back. The sociodemographic characteristics of the participants are summarized in Table 1. The mean age was $15.42 \pm 1.14$ years, with $53.3 \%$ females, $25.9 \%$ smokers, and $11.9 \%$ with separated/divorced parents. The mean AUDIT score in our sample was $6.46 \pm 8.44($ median $=2)$; also, $507(28.0 \%)$

Table 1 Sociodemographic characteristics of the sample population $(\mathrm{N}=1810)$

Frequency (\%)

\begin{tabular}{ll}
\hline Sex & \\
Male & $844(46.7 \%)$ \\
Female & $963(53.3 \%)$ \\
Parents status & \\
Living together & $1581(88.1 \%)$ \\
Separate & $213(11.9 \%)$ \\
Smoking status & \\
Yes & $468(25.9 \%)$ \\
No & $1342(74.1 \%)$
\end{tabular}

Mean \pm SD

Age (years)

$15.42+1.14$

Body Mass Index (kg/m2)

$21.95 \pm 4.21$

Household crowding index

$1.01 \pm 0.64$ 
had high risk of hazardous alcohol drinking (HAD) (AUDIT scores $\geq 8$ ) [95\% CI 0.259-0.301].

\section{Validation of the AUDIT scale Subsample 1}

Factor analysis The factor analysis of the AUDIT scale was run on the full sample (Total $n=905$ ), and none of the items has been removed. Items converged on a onefactor solution with Eigenvalues greater than 1, accounting for a total of $85.88 \%$ of the variance. The Kaiser-Meyer-Olkin measure of sampling adequacy was 0.832 , with a significant Bartlett's sphericity test $(p<$ 0.001). Moreover, a high Cronbach's alpha was found for the full scale (0.978) (Table 2).

\section{Subsample 2}

Confirmatory factor analysis A confirmatory factor analysis was run on subsample $2(n=905)$, using the one-factor structure obtained in Sample 1. The results were as follows: the Maximum Likelihood Chi-Square = 257 and Degrees of Freedom $=104$, which gave a $x^{2} / \mathrm{df}=$ 2.4. For non-centrality fit indices, the Steiger-Lind RMSEA was 0.10 [0.084-0.155]. Moreover, the Joreskog GFI equaled 0.91 and AGFI equaled 0.92.

Bivariate analysis The results of the bivariate analysis showed a significantly higher AUDIT score in adolescents whose parents are separated compared to those whose parents live together and in females compare to males. A higher mean AUDIT score was found in Beirut and Mount Lebanon compared to North, South, and Bekaa $(p<0.001$ for the whole trend). The post hoc analysis showed a significantly different mean AUDIT scores between Beirut vs. North $(p=0.002)$, Beirut vs. South $(p<$
0.001), Beirut vs. Bekaa $(p<0.001)$, Mount Lebanon vs. South $(p<0.001)$, and Mount Lebanon vs. Bekaa $(p<$ 0.001 ). No significant correlation was found between the AUDIT score and age $(r=-0.01 ; p=0.683)$. Furthermore, higher AUDIT scores were significantly associated with higher house crowding index $(r=0.084 ; p=0.001)$, higher fear $(r=0.164 ; p<0.001)$, avoidance $(r=0.09 ; p<0.001)$, bullying victimization $(r=0.381 ; p<0.001)$, cigarette $(r=$ $0.499 ; p<0.001)$ and waterpipe dependence $(r=0.422$; $p<0.001)$, internet addiction $(r=0.318 ; p<0.001)$, and childhood psychological $(r=0.479 ; p<0.001)$, neglect $(r=$ $0.112 ; p<0.001)$, physical $(r=0.440 ; p<0.001)$ and sexual $(r=0.406 ; p<0.001)$ abuse (Tables 3 and 4$)$.

Multivariable analysis The results of a stepwise linear regression, taking the AUDIT score as the dependent variable, showed that higher AUDIT scores were significantly associated with higher cigarette (Beta $=0.527 ; p<0.001)$ and waterpipe (Beta $=0.299 ; p<0.001$ ) dependence, higher childhood sexual abuse (Beta $=0.656 ; p<0.001$ ) and neglect (Beta $=0.126 ; p<0.001$ ), higher bullying victimization (Beta $=0.236 ; p<0.001)($ Table 5$)$.

\section{Discussion}

To our knowledge, this is the first national study to determine factors related to alcohol use disorder among adolescents. Our research revealed that higher AUD in Lebanese adolescents was associated with cigarette and waterpipe smoking, child abuse and neglect and bullying.

Concerning psychometric properties in our study, the AUDIT score showed an outstanding Cronbach's alpha of 0.978 , in agreement with other studies $[29,71]$. Moreover, the one-factor model of the Arabic version was better than that of the Portuguese model [72] in terms of internal consistency and number of factors, making

Table 2 Principal component analysis results of the promax rotation of the AUDIT scale

\begin{tabular}{|c|c|c|}
\hline Question & Item & $\begin{array}{l}\text { Loading } \\
\text { factor }\end{array}$ \\
\hline Has a relative or friend or a doctor or another health worker been concerned about your drinking or suggested you cut down? & 10 & 0.965 \\
\hline Have you or someone else been injured as a result of your drinking? & 9 & 0.964 \\
\hline How often during the last year have you had a feeling of guilt or remorse after drinking? & 7 & 0.963 \\
\hline $\begin{array}{l}\text { How often during the last year have you needed a first drink in the morning to get yourself going after a heavy drinking } \\
\text { session? }\end{array}$ & 6 & 0.956 \\
\hline $\begin{array}{l}\text { How often during the last year have you been unable to remember what happened the night before because you had been } \\
\text { drinking? }\end{array}$ & 8 & 0.951 \\
\hline How often during the last year have you found that you were not able to stop drinking once you had started? & 4 & 0.943 \\
\hline How often do you have six or more drinks on one occasion? & 3 & 0.938 \\
\hline How often during the last year have you failed to do what was normally expected from you because of drinking? & 5 & 0.929 \\
\hline How many drinks containing alcohol do you have on a typical day when you are drinking? & 2 & 0.920 \\
\hline How often do you have a drink containing alcohol? & 1 & 0.711 \\
\hline
\end{tabular}


Table 3 Bivariate analysis of categorical variables associated with the AUDIT score

\begin{tabular}{|c|c|c|c|}
\hline & \multicolumn{2}{|c|}{ AUDIT total score } & \multirow{2}{*}{$\begin{array}{l}P \\
\text {-value }\end{array}$} \\
\hline & Median & IQR & \\
\hline \multicolumn{4}{|l|}{ Sex } \\
\hline Male & 1.00 & 7.00 & \multirow[t]{2}{*}{0.006} \\
\hline Female & 2.00 & 13.00 & \\
\hline \multicolumn{4}{|l|}{ Parents status } \\
\hline Living together & 1.00 & 7.00 & \multirow[t]{2}{*}{$<0.001$} \\
\hline Separate & 17.00 & 17.00 & \\
\hline \multicolumn{4}{|l|}{ Governorate } \\
\hline Beirut & 2.00 & 21.00 & \multirow[t]{5}{*}{$<0.001$} \\
\hline Mount Lebanon & 4.00 & 17.00 & \\
\hline North & 2.00 & 10.00 & \\
\hline South & 1.00 & 5.00 & \\
\hline Bekaa & 1.00 & 8.00 & \\
\hline
\end{tabular}

Numbers in bold indicate significant $p$-values; IQR Interquartile range; LWDS Lebanese Waterpipe Dependence Scale; FTND Fagerstrom Nicotine Dependence Test; IAT Internet Addiction Test

this tool useful in identifying risk-taking, signs of addiction, and unhealthy alcohol use among adolescents in Lebanon. Accordingly, using the AUDIT scale to assess AUD among Lebanese adolescents is recommended. However, additional studies are needed to further examine validity features of the AUDIT scale (face validity and criterion validity).

Our results showed that the prevalence of AUD risk among Lebanese adolescents was $28.0 \%$, in line with other studies [2, 4]. Besides the correlations with the psychological factors identified in this research, this proportion may also be related to the normalization of

Table 4 Bivariate analysis of continuous variables associated with the AUDIT score

\begin{tabular}{lll}
\hline & Correlation coefficient & $\boldsymbol{P}$-value \\
\hline Age & -0.010 & 0.683 \\
Liebowitz- fear score & 0.164 & $<\mathbf{0 . 0 0 1}$ \\
Liebowitz- avoidance score & 0.090 & $<\mathbf{0 . 0 0 1}$ \\
Bullying/victimization score & 0.381 & $<\mathbf{0 . 0 0 1}$ \\
Waterpipe dependence (LWDS score) & 0.422 & $<\mathbf{0 . 0 0 1}$ \\
Cigarette dependence (FTND score) & 0.499 & $<\mathbf{0 . 0 0 1}$ \\
Internet addiction & 0.318 & $<\mathbf{0 . 0 0 1}$ \\
House crowding index & 0.084 & $\mathbf{0 . 0 0 1}$ \\
Physical activity score & -0.011 & 0.656 \\
Psychological abuse scale & 0.479 & $<\mathbf{0 . 0 0 1}$ \\
Child abuse neglect scale & 0.112 & $\mathbf{0 . 0 0 6}$ \\
Child abuse physical scale & 0.440 & $<\mathbf{0 . 0 0 1}$ \\
Child abuse sexual scale & 0.406 & $<\mathbf{0 . 0 0 1}$ \\
\hline
\end{tabular}

alcohol use, its broad availability, particularly in Beirut and Mount Lebanon, the inaction of the government, in addition to existing indefinite policies regarding the illegal sale of alcohol to minors, low excise taxes on alcohol, weak regulatory framework for alcohol advertising and promotion, lack of effectively reported adverse effects of alcohol consumption, and the impact of friends and cousins on the young population [21].

A notably higher mean AUDIT score was found in Beirut and Mount Lebanon compared to the other districts. This might be related to the religious distribution in those two districts, while North, South, and Bekaa have most of the Lebanese Muslim rural populations $[21,23]$. This distribution further corroborates the validity of the AUDIT scale. Indeed, in Islam, alcohol drinking is forbidden by the Qur'an and is considered to be a satanic act. Abstaining from alcohol consumption is primarily linked to its illegality but also to the feeling of guilt that followers of Islam may have if they drink [73].

\section{Cigarette and waterpipe dependence and AUD}

In the present study, a higher dependence on cigarette smoking was remarkably associated with higher AUDIT scores, in agreement with other studies [7, 74]. Also, waterpipe smoking was related to higher AUDIT scores, with a few previous studies showing this association [74, 75]. In fact, waterpipe smoking is addictive and associated with nicotine dependence among adolescents [76]. It is generally assumed that young smokers are at higher vulnerability to AUD than non-smokers at equal rates of alcohol consumption, consistent with the results reported by Kandel and Chen [77]. To clarify the association between smoking and AUD, Grucza et al., 2006 suggested that a pharmacological influence may result from smoking by expanding the vulnerability of smokers to develop AUD [7]. A genetic predisposition or other obscure factors may also be involved in the initiation of youth smoking, which may play a role in developing AUD [7].

\section{Childhood sexual abuse, neglect, and AUD}

Our results highlighted that an increase in childhood sexual abuse was correlated with higher AUD, consistent with the findings of other studies documenting this association in adolescents [12, 78]. Several explanatory models are suggested to clarify this association. First, the relationship is likely based on psychiatric issues, as childhood sexual victimization frequently leads to depression and anxiety [79]. Young people who do not have the appropriate system to deal with bad experiences can drink alcohol to cope with their traumatic childhood or try to escape it, and increase their alcohol consumption, thinking they are solving their problems and falling into alcohol misuse instead [78, 80]. Moreover, several studies 
Table 5 Multivariable analysis: Linear regression taking the AUDIT score as the dependent variable

\begin{tabular}{|c|c|c|c|c|c|}
\hline \multirow[t]{2}{*}{ Variable } & \multirow{2}{*}{$\begin{array}{l}\text { Unstandardized } \\
\text { Beta }\end{array}$} & \multirow{2}{*}{$\begin{array}{l}\text { Standardized } \\
\text { Beta }\end{array}$} & \multirow{2}{*}{$\begin{array}{l}\boldsymbol{p}^{-} \\
\text {value }\end{array}$} & \multicolumn{2}{|c|}{ Confidence Interval } \\
\hline & & & & Lower & Upper \\
\hline Cigarette dependence & 0.527 & 0.191 & $<0.001$ & 0.362 & 0.692 \\
\hline Waterpipe dependence & 0.299 & 0.331 & $<0.001$ & 0.246 & 0.352 \\
\hline Child abuse sexual scale & 0.656 & 0.301 & $<0.001$ & 0.569 & 0.743 \\
\hline Child abuse neglect scale & 0.126 & 0.154 & $<0.001$ & 0.096 & 0.156 \\
\hline Bullying/victimization score & 0.236 & 0.204 & $<0.001$ & 0.191 & 0.281 \\
\hline
\end{tabular}

Variables entered in the model: sex, parents' status, IAT score, LWDS-11 score, FTND score, Liebowitz fear score, Liebowitz avoidance score, Psychological abuse scale, Child abuse neglect scale, Child abuse physical scale, Child abuse sexual scale and Bullying/victimization score, house crowding index

found that antisocial behaviors can also be a consequence of childhood victimization [81, 82]; thus, youth involved in deviant peer groups will experience more AUD [80] .

Furthermore, higher neglect was associated with significantly higher AUDIT scores, in line with previous research [83]. Unfavorable life experiences during childhood may lead to developing post-traumatic stress disorder, which in turn might lead to an inescapable effect on biological stress response mechanisms and mental health, driving victims to respond to their previous traumatic experiences by drinking alcohol [84]. Also, ignored children cannot develop a valuable relationship with their inert primary caregiver and are more prone to build up a sense of vulnerability, poor social and companionship skills $[85,86]$, and degradation of selfconfidence and self-control [83], thereby leading to increased alcohol use.

\section{Bullying victimization and AUD}

Our findings showed that higher bullying victimization was significantly associated with more AUD, concurring with those of previous research $[13,14]$. Bullying itself is a major global health problem with severe consequences [87, 88], long linked to issues of self-worth [89, 90], loneliness, depression, anxiety, and physical symptoms [91]. It is suggested that AUD is a mean to cope with symptoms of mood disorders developed after being bullied [91], to ease the anxiety and escape reality. Some may use alcohol as a way to emphasize their social image and improve their previously diminished self-worth [91]. Additionally, youth tend to seek a peer-to-peer environment because they cannot solve bullying problems on their own, which seems to increase the susceptibility to engage in AUD [14].

This research has some limitations and a few potential weaknesses worth mentioning. First, given its crosssectional design, this study showed risk factors associated with Alcohol Use Disorder but could not establish causality. The height and weight of the students were self-reported and not measured. Also, although 18 religious communities share their convictions freely in Lebanon, some still perceive alcohol as a taboo, and consequently, some schools refused to participate in our investigation. Participants were evaluated using a scoring tool and not clinical assessment tests; therefore, the precision of responses could not be affirmed. Except for the IAT, all the scales used have not been validated among Lebanese adolescents, which might have led to a nondifferential information bias. Finally, a selection bias cannot be ruled out because of the selection process of schools, as public schools were not included in the study. However, the relatively large sample size allows a close approximation of the findings to the general adolescent population, especially since no study of this type, taking into consideration a representative sample from all regions, was previously conducted in Lebanon.

\section{Conclusion}

Our findings revealed that cigarette and waterpipe dependence, bullying victimization, childhood sexual abuse and neglect were associated with higher AUDIT scores. Recognizing these factors is essential for parents and healthcare professionals who can use this data for early intervention. The prevalence of alcohol use disorder found in our study should exhort the government to include a minimum legal age to drink, regulate advertising of alcohol, set fines for those who sell alcohol and promote it in minors, particularly those targeting adolescents. Increased efforts are needed to collect data and determine the extent of alcohol consumption and translate it into evidence-based guidelines that may be used to direct policy and practice.

\section{Abbreviations}

GSHS: Global school-based student health survey; BMI: Body mass index; AUDIT: Alcohol use disorders identification test; LSAS: Liebowitz social anxiety scale; IAT: Internet addiction test; LWDS-11: Lebanon waterpipe dependence scale-11; FTND: Fagerstrom test for nicotine dependence; CASRS: Child abuse self-report scale; RMSEA: Root mean square error of approximation; GFI: Goodness of fit index; AGFI: Adjusted goodness of fit index; HAD: Hazardous alcohol drinking 


\section{Acknowledgments}

The authors would like to thank Dr. Jad Chidiac and Dr. Melissa Chahine for their help in data collection and data entry, and the teachers and supervisors for helping to maintain discipline in the classrooms as students completed the questionnaire. Special thanks to all the students who helped us as well.

\section{Authors' contributions}

MS, SO and SH conceived and designed the survey. $\mathrm{CH}, \mathrm{PS}$ and $\mathrm{SH}$ were involved in the statistical analysis and data interpretation. $\mathrm{JH}$ wrote the manuscript. RH, PS and HS reviewed the manuscript. MA and JH involved in the data collection and data entry. HS edited the paper for English language. All authors read the manuscript, critically revised it for intellectual content, and approved the final version.

\section{Funding}

None.

\section{Availability of data and materials}

The authors do not have the right to share any data information as per their institutions policies.

\section{Ethics approval and consent to participate}

The Psychiatric Hospital of the Cross Ethics and Research Committee approved this study protocol (HPC-012-2019). The students' parents gave their written informed consent before starting the data collection.

\section{Consent for publication}

not applicable.

\section{Competing interests}

The authors declare that they have no competing interest.

\section{Author details}

${ }^{1}$ Faculty of Medicine and Medical Sciences, Holy Spirit University of Kaslik (USEK), Jounieh, Lebanon. ${ }^{2}$ INSPECT-LB: Institut National de Santé Publique, Épidémiologie Clinique et Toxicologie, Beirut, Lebanon. ${ }^{3}$ Faculty of Pharmacy, Lebanese University, Hadat, Lebanon. ${ }^{4}$ Faculty of Medicine, Lebanese University, Hadat, Lebanon. ${ }^{5}$ Research and Psychology Departments, Psychiatric Hospital of the Cross, Jal Eddib, Lebanon. 6 Université de Limoges, UMR 1094, Neuroépidémiologie Tropicale, Institut d'Epidémiologie et de Neurologie Tropicale, GEIST, 87000 Limoges, France. ${ }^{7}$ Drug Information Center, Order of Pharmacists of Lebanon, Beirut, Lebanon. ${ }^{8}$ School of Pharmacy, Lebanese International University, Beirut, Lebanon. ${ }^{9}$ Faculty of Arts and Sciences, Holy Spirit University of Kaslik (USEK), Jounieh, Lebanon.

\section{Received: 24 January 2020 Accepted: 30 April 2020}

Published online: 11 May 2020

\section{References}

1. World Health Organization. Maternal, newborn, child and adolescent health. Adolescent development. Available from: https://www.who.int/maternal_ child_adolescent/topics/adolescence/development/en/. [Accessed 17 Jan 2020].

2. Ghandour L, Afifi R, Fares S, El Salibi N, Rady A. Time trends and policy gaps: the case of alcohol misuse among adolescents in Lebanon. Subs Use Misuse. 2015;50(14):1826-39.

3. Hadland SE, Knight JR, Harris SK. Alcohol use disorder: a pediatric-onset condition needing early detection and intervention. Pediatrics. 2019;143(3): e20183654.

4. Homeland security digital library. Results from the 2011 National Survey on Drug Use and Health: Mental Health Findings, available from: https://www. hsdl.org/?view\&did=730763. Accessed 17 Jan 2020.

5. American Psychiatric Association: Diagnostic and statistical manual of mental disorders (DSM-5 $\left.{ }^{\oplus}\right) ; 2013$.

6. World Health Organization. Management of substance abuse: Global status report on alcohol and health 2018, available from: https://www.who.int/ substance_abuse/publications/global_alcohol_report/en/. Accessed 17 Jan 2020.

7. Grucza RA, Bierut LJ. Cigarette smoking and the risk for alcohol use disorders among adolescent drinkers. Alcohol Clin Exp Res. 2006:30(12): 2046-54.
8. Mokdad AH, Marks JS, Stroup DF, Gerberding JL. Actual causes of death in the United States, 2000. Jama. 2004;291(10):1238-45.

9. Ko CH, Yen J-Y, Yen CF, Chen CS, Weng CC, Chen CC. The association between internet addiction and problematic alcohol use in adolescents: the problem behavior model. Cyberpsychol Behav. 2008;11(5):571-6.

10. Morris EP, Stewart SH, Ham LS. The relationship between social anxiety disorder and alcohol use disorders: a critical review. Clin Psychol Rev. 2005; 25(6):734-60.

11. LeTendre ML, Reed MB. The effect of adverse childhood experience on clinical diagnosis of a substance use disorder: results of a nationally representative study. Subst Use Misuse. 2017;52(6):689-97.

12. Moran PB, Vuchinich S, Hall NK. Associations between types of maltreatment and substance use during adolescence. Child Abuse Negl. 2004;28(5):565-74.

13. Cardoso JB, Szlyk HS, Goldbach J, Swank P, Zvolensky MJ. General and ethnic-biased bullying among Latino students: exploring risks of depression, suicidal ideation, and substance use. J Immigr Minor Health. 2018;20(4):816-22.

14. Lambe $\amalg$, Craig WM. Bullying involvement and adolescent substance use: a multilevel investigation of individual and neighbourhood risk factors. Drug Alcohol Depend. 2017;178:461-8.

15. Dyer ML, Easey KE, Heron J, Hickman M, Munafò MR. Associations of child and adolescent anxiety with later alcohol use and disorders: a systematic review and meta-analysis of prospective cohort studies. Addiction. 2019; 114(6):968-82

16. Shin SH, Hassamal S, Groves LP. Examining the role of psychological distress in linking childhood maltreatment and alcohol use in young adulthood. Am J Addict. 2015;24(7):628-36.

17. Maynard BR, Vaughn MG, Salas-Wright CP, Vaughn S. Bullying victimization among school-aged immigrant youth in the United States. J Adolesc Health. 2016:58(3):337-44.

18. Modecki KL, Minchin J, Harbaugh AG, Guerra NG, Runions KC. Bullying prevalence across contexts: a meta-analysis measuring cyber and traditional bullying. J Adolesc Health. 2014;55(5):602-11.

19. Bradshaw CP, Waasdorp TE, Goldweber A, Johnson SL. Bullies, gangs, drugs, and school: understanding the overlap and the role of ethnicity and urbanicity. J Youth Adolescence. 2013:42(2):220-34.

20. Kodish T, Herres J, Shearer A, Atte T, Fein J, Diamond G. Bullying, depression, and suicide risk in a pediatric primary care sample. Crisis. 2016.

21. Yassin N, Afifi R, Singh N, Saad R, Ghandour $L$. "There is zero regulation on the selling of alcohol": the voice of the youth on the context and determinants of alcohol drinking in Lebanon. Qual Health Res. 2018;28(5):733-44.

22. Ghandour L, Chalak A, El-Aily A, Yassin N, Nakkash R, Tauk M, El Salibi N, Heffron M, Afifi R. Alcohol consumption in the Arab region: what do we know, why does it matter, and what are the policy implications for youth harm reduction? Int J Drug Policy. 2016;28:10-33.

23. Yazbek J-C, Haddad R, Bou Khalil R, Hlais S, Rizk GA, Rohayem J, Richa S. Prevalence and correlates of alcohol abuse and dependence in Lebanon: results from the Lebanese epidemiologic survey on alcohol (LESA). J Addict Dis. 2014;33(3):221-33.

24. Obeid S, Akel M, Haddad C, Fares K, Sacre H, Salameh P, Hallit S. Factors associated with alcohol use disorder: the role of depression, anxiety, stress, alexithymia and work fatigue- a population study in Lebanon. BMC Public Health. 2020;20(1):245.

25. Centers for Disease Control and Prevention. Global school-based student health survey. Retrieved from http://www.cdc.gov/GSHS/ [Accessed 30 Oct 2019].

26. World Health Organization. Alcohol Use Disorders Identification Test (AUDIT). Available from: https://www.drugabuse.gov/sites/default/files/files/ AUDIT.pdf. Accessed 17 Jan 2020.

27. World Health Organization. Management of substance abuse. Lexicon of alcohol and drug terms published by the World Health Organization. Available from: https://www.who.int/substance_abuse/terminology/who_ lexicon/en/. Accessed 17 Jan 2020.

28. Liskola J, Haravuori H, Lindberg N, Niemelä S, Karlsson L, Kiviruusu O, Marttunen M. AUDIT and AUDIT-C as screening instruments for alcohol problem use in adolescents. Drug Alcohol Depend. 2018;188:266-73.

29. Quintero LAM, MdIVM J, Rojas-Solís JL, Molleda CB, Chilaca AS, FJR D. Psychometric properties of the alcohol use disorder identification test (AUDIT) in adolescents and young adults from Suthern Mexico: alcohol use disorder identification test (AUDIT) in young Mexicans. Alcohol. 2019;81:39_ 46. https://doi.org/10.1016/j.alcohol.2019.05.002. 
30. Almarri TS, Oei TP, Amir T. Validation of the alcohol use identification test in a prison sample living in the Arabian gulf region. Subst Use Misuse. 2009; 44(14):2001-13.

31. Salamé J, Barbour B, Salameh P. Do personal beliefs and peers affect the practice of alcohol consumption in university students in Lebanon? East Mediterr Health J. 2013;19(4):340-7.

32. Haddad C, Zakhour M, Akel M, Honein K, Akiki M, Hallit S, Obeid S. Factors associated with body dissatisfaction among the Lebanese population. Eat Weight Disord-Stud Anorexia, Bulimia Obes. 2019;24(3):507-19.

33. Haddad C, Obeid S, Akel M, Honein K, Akiki M, Azar J, Hallit S. Correlates of orthorexia nervosa among a representative sample of the Lebanese population. Eat Weight Disord-Stud Anorexia, Bulimia Obes. 2019;24(3):481-93.

34. Obeid S, Haddad C, Akel M, Fares K, Salameh P, Hallit S. Factors associated with the adults' attachment styles in Lebanon: the role of alexithymia, depression, anxiety, stress, burnout, and emotional intelligence. Perspect Psychiatr Care. 2019;55(4):607-17.

35. Haddad C, Hallit R, Akel M, Honein K, Akiki M, Kheir N, Obeid S, Hallit S. Validation of the Arabic version of the ORTO-15 questionnaire in a sample of the Lebanese population. Eat Weight Disord. 2019. https://doi.org/10. 1007/s40519-019-00710-y.

36. Khansa W, Haddad C, Hallit R, Akel M, Obeid S, Haddad G, Soufia M, Kheir N, Abi CEH, Khoury R. Interaction between anxiety and depression on suicidal ideation, quality of life, and work productivity impairment: results from a representative sample of the Lebanese population. Perspect Psychiatr Care. 2020;56(2):270-79. https://doi.org/10.1111/ppc.12423.

37. Lahoud N, Zakhour M, Haddad C, Salameh P, Akel M, Fares K, Hallit S, Obeid S. Burnout and its relationships with alexithymia, stress, self-esteem, depression, alcohol use disorders, and emotional intelligence: results from a Lebanese cross-sectional study. J Nerv Ment Dis. 2019;207(8):642-50.

38. Obeid S, Fares K, Haddad C, Lahoud N, Akel M, Zakhour M, Kheir N, Salameh $P$, Hallit S. Construction and validation of the Lebanese fear of relationship commitment scale among a representative sample of the Lebanese population. Perspect Psychiatr Care. 2020;56(2):280-89. https://doi.org/10. 1111/ppc.12424

39. Obeid S, Sacre H, Haddad C, Akel M, Fares K, Zakhour M, Kheir N, Salameh $P$, Hallit $S$. Factors associated with fear of intimacy among a representative sample of the Lebanese population: the role of depression, social phobia, self-esteem, intimate partner violence, attachment, and maladaptive schemas. Perspect Psychiatr Care. 2019. https://doi.org/10.1111/ppc.12438.

40. Obeid S, Akel M, Haddad C, Fares K, Sacre H, Salameh P, Hallit S. Factors associated with alexithymia among the Lebanese population: results of a cross-sectional study. BMC Psychol. 2019;7(1):80.

41. Saade S, Hallit S, Haddad C, Hallit R, Akel M, Honein K, Akiki M, Kheir N, Obeid S. Factors associated with restrained eating and validation of the Arabic version of the restrained eating scale among an adult representative sample of the Lebanese population: a cross-sectional study. J Eat Disord. 2019;7(1):24.

42. Zakhour M, Haddad C, Salameh P, Akel M, Fares K, Sacre H, Hallit S, Obeid S. Impact of the interaction between alexithymia and the adult attachment styles in participants with alcohol use disorder. Alcohol. 2020;83:1-8.

43. Zeidan RK, Haddad C, Hallit R, Akel M, Honein K, Akiki M, Kheir N, Hallit S, Obeid S. Validation of the Arabic version of the binge eating scale and correlates of binge eating disorder among a sample of the Lebanese population. J Eat Disord. 2019;7(1):40.

44. Sfeir E, Haddad C, Salameh P, Sacre H, Hallit R, Akel M, Honein K, Akiki M, Kheir N, Obeid S. Binge eating, orthorexia nervosa, restrained eating, and quality of life: a population study in Lebanon. Eat Weight Disord. 2019 https://doi.org/10.1007/s40519-019-00831-4.

45. Obeid S, Haddad C, Zakhour M, Fares K, Akel M, Salameh P, Hallit S. Correlates of self-esteem among the Lebanese population: a cross-sectional study. Psychiatr Danub. 2019;31(4):429-39.

46. Fares K, Hallit S, Haddad C, Akel M, Khachan T, Obeid S. Relationship between cosmetics use, self-esteem, and self-perceived attractiveness among Lebanese women. J Cosmet Sci. 2019;70(1):47-56.

47. Hallit S, Sacre H, Haddad C, Malaeb D, Al Karaki G, Kheir N, Hajj A, Hallit R, Salameh P. Development of the Lebanese insomnia scale (LIS-18): a new scale to assess insomnia in adult patients. BMC Psychiatry. 2019;19(1):1-10.

48. Obeid S, Haddad C, Salame W, Kheir N, Hallit S. Xenophobic attitudes, behaviors and coping strategies among Lebanese people toward immigrants and refugees. Perspect Psychiatr Care. 2019;55(4):710-7.

49. Obeid S, Saade S, Haddad C, Sacre H, Khansa W, Al Hajj R, Kheir N, Hallit S. Internet addiction among Lebanese adolescents: the role of self-esteem, anger, depression, anxiety, social anxiety and fear, impulsivity, and aggression-a cross-sectional study. J Nerv Ment Dis. 2019;207(10):838-46.

50. Hallit S, Hajj A, Sacre H, Al Karaki G, Malaeb D, Kheir N, Salameh P, Hallit R. Impact of sleep disorders and other factors on the quality of life in general population: a cross-sectional study. J Nerv Ment Dis. 2019;207(5):333-9.

51. Abi Doumit C, Haddad C, Sacre H, Salameh P, Akel M, Obeid S, Akiki M, Mattar E, Hilal N, Hallit S. Knowledge, attitude and behaviors towards patients with mental illness: Results from a national Lebanese study. PLoS One. 2019;14(9):e0222172.

52. Rahme C, Haddad C, Akel M, et al. Factors associated with violence against women in a representative sample of the Lebanese population: results of a cross-sectional study. Arch Womens Ment Health; 2020. https://doi.org/10. 1007/s00737-020-01022-2.

53. Rahme C, Haddad C, Akel M, et al. Does Stockholm syndrome exist in Lebanon? Results of a cross-sectional study considering the factors associated with violence against women in a Lebanese representative sample. J Interpers Violence. 2020:886260519897337.

54. Obeid S, Lahoud N, Haddad C, et al. Factors associated with anxiety among the Lebanese population: the role of alexithymia, self-esteem, alcohol use disorders, emotional intelligence and stress and burnout. Int J Psychiatry Clin Pract. 2020:1-12. https://doi.org/10.1080/13651501.2020.1723641.

55. Hallit S, Obeid S, Haddad C, et al. Construction of the Lebanese anxiety scale (LAS-10): a new scale to assess anxiety in adult patients. Int J Psychiatry Clin Pract. 2020:1-8. https://doi.org/10.1080/13651501.2020.1744662.

56. Nakhoul L, Obeid S, Sacre H, et al. Attachment style and addictions (alcohol, cigarette, waterpipe and internet) among Lebanese adolescents: a national study. BMC Psychol. 2020;8:33. https://doi.org/10.1186/s40359-020-00404-6.

57. Melki I, Beydoun H, Khogali M, Tamim H, Yunis K. Household crowding index: a correlate of socioeconomic status and inter-pregnancy spacing in an urban setting. J Epidemiol Community Health. 2004;58(6):476-80.

58. Bohn MJ, Babor TF, Kranzler HR. The alcohol use disorders identification test (AUDIT): validation of a screening instrument for use in medical settings. J Stud Alcohol. 1995;56(4):423-32.

59. Liebowitz MR, Klein D. Social phobia: Guilford publications; 1991.

60. Rytwinski NK, Fresco DM, Heimberg RG, Coles ME, Liebowitz MR, Cissell S, Stein MB, Hofmann SG. Screening for social anxiety disorder with the selfreport version of the Liebowitz social anxiety scale. Depress Anxiety. 2009; 26(1):34-8.

61. Hawi NS. Arabic validation of the internet addiction test. Cyberpsychol Behav Soc Netw. 2013;16(3):200-4.

62. Samaha AA, Fawaz M, El Yahfoufi N, Gebbawi M, Abdallah H, Baydoun SA, Ghaddar A, Eid AH. Assessing the psychometric properties of the internet addiction test (IAT) among Lebanese college students. Front Public Health. 2018;6:365.

63. Salameh P, Waked M, Aoun Z. Waterpipe smoking: construction and validation of the Lebanon Waterpipe dependence scale (LWDS-11). Nicotine Tob Res. 2008;10(1):149-58.

64. Heatherton TF, Kozlowski LT, Frecker RC, FAGERSTROM KO. The Fagerström test for nicotine dependence: a revision of the Fagerstrom tolerance questionnaire. Br J Addict. 1991;86(9):1119-27.

65. Mohammadkhani P, Mohammadi M, Nazari M, Salavati M, Razzaghi O. DEV ELOPMENT, validation and reliability of child abuse self report scale (CASRS) in IRANIAN students. Med J Islamic Repub Iran (MJIRI). 2003;17(1):51-8.

66. Hadianfard $\mathrm{H}$. Child abuse in group of children with attention deficithyperactivity disorder in comparison with normal children. Int J Community Based Nursi Midwifery. 2014;2(2):77.

67. Step S. Skills for Social and Academic Success. 2013. Illinois Bully Scale: Student Version. http://www.secondstep org/Portals/0 G. Accessed 17 Jan 2020.

68. Miller R Jr. Simultaneous statistical inference. NY: McGraw-hill; 1966.

69. Bursac Z, Gauss CH, Williams DK, Hosmer DW. Purposeful selection of variables in logistic regression. Source Code Biol Med. 2008;3(1):17.

70. Marsh HW, Hau K-T, Wen Z. In search of golden rules: comment on hypothesis-testing approaches to setting cutoff values for fit indexes and dangers in overgeneralizing Hu and Bentler's (1999) findings. Struct Equ Model. 2004;11(3):320-41.

71. Santis R, Garmendia ML, Acuña G, Alvarado ME, Arteaga O. The alcohol use disorders identification test (AUDIT) as a screening instrument for adolescents. Drug Alcohol Depend. 2009;103(3):155-8.

72. García Carretero MÁ, Novalbos Ruiz JP, DELGADO J, MARTíNEZ M, COF GONZÁLEZ. Validation of the Alcohol Use Disorders Identification Test in 
university students: AUDIT and AUDIT-C. Adicciones. 2016;28(4):194-204. https://doi.org/10.20882/adicciones.775.

73. Assanangkornchai S, Talek M, Edwards JG. Influence of Islam and the globalized alcohol industry on drinking in Muslim countries. Addiction. 2016;111(10):1715-6.

74. Richter L, Pugh BS, Smith PH, Ball SA. The co-occurrence of nicotine and other substance use and addiction among youth and adults in the United States: implications for research, practice, and policy. Am J Drug Alcohol Abuse. 2017:43(2):132-45.

75. Ramji R, Arnetz BB, Nilsson M, Wiklund Y, Jamil H, Maziak W, Arnetz J. Waterpipe use in adolescents in northern Sweden: association with mental well-being and risk and health behaviours. Scand J Public Health. 2018;46(8): 867-76.

76. Bahelah R, DiFranza JR, Ward KD, Fouad FM, Eissenberg T, Taleb ZB, Jaber R, Osibogun O, Maziak W. Correlates of nicotine dependence among adolescent waterpipe smokers. Drug Alcohol Depend. 2016;168: 230-8.

77. Kandel DB, Chen K. Extent of smoking and nicotine dependence in the United States: 1991-1993. Nicotine Tob Res. 2000;2(3):263-74.

78. Tonmyr L, Shields M. Childhood sexual abuse and substance abuse: a gender paradox? Child Abuse Negl. 2017;63:284-94.

79. Simpson TL, Miller WR. Concomitance between childhood sexual and physical abuse and substance use problems: a review. Clin Psychol Rev. 2002;22(1):27-77.

80. Widom CS, Hiller-Sturmhöfel S. Alcohol abuse as a risk factor for and consequence of child abuse. Alcohol Res Health. 2001;25(1):52.

81. Miller BA, Maguin E, Downs WR. Alcohol, Drugs, and Violence in Children's Lives. In: Galanter M. et al. (eds) Recent Developments in Alcoholism. Recent Development in Alcoholism, vol 13. Boston: Springer; 2002.

82. Widom CS. The cycle of violence. Science. 1989;244(4901):160-6.

83. Chen W-Y, Propp J, Delara E, Corvo K. Child neglect and its association with subsequent juvenile drug and alcohol offense. Child Adolesc Soc Work J. 2011:28(4):273

84. De Bellis MD. Developmental traumatology: a contributory mechanism for alcohol and substance use disorders. Psychoneuroendocrinology. 2002; 27(1-2):155-70.

85. Crittenden PM, Ainsworth MD. 14 child maltreatment and attachment theory. London, England: Cambridge University Press; 1989.

86. Howes $C$, Eldredge R. Responses of abused, neglected, and non-maltreated children to the behaviors of their peers. J Appl Dev Psychol. 1985;6(2-3): 261-70.

87. Pigozi PL, Machado AL. Bullying during adolescence in Brazil: an overview. Ciên Saúde Colet. 2015;20(11):3509-22. https://doi.org/10.1590/1413812320152011.05292014

88. Neto AAL. Bullying: comportamento agressivo entre estudantes. J Pediatr. 2005;81(5):164-72

89. Brito CC, Oliveira MT. Bullying and self-esteem in adolescents from public schools. J Pediatr. 2013:89(6):601-7.

90. Bandeira CdM, Hutz CS: As implicações do bullying na auto-estima de adolescentes. 2010

91. Elkins C. Bullying and substance abuse: who it affects and why. 2019.

\section{Publisher's Note}

Springer Nature remains neutral with regard to jurisdictional claims in published maps and institutional affiliations.

Ready to submit your research? Choose BMC and benefit from:

- fast, convenient online submission

- thorough peer review by experienced researchers in your field

- rapid publication on acceptance

- support for research data, including large and complex data types

- gold Open Access which fosters wider collaboration and increased citations

- maximum visibility for your research: over $100 \mathrm{M}$ website views per year

At $\mathrm{BMC}$, research is always in progress.

Learn more biomedcentral.com/submissions 